\title{
Research on Chinese Rural Resident' Energy-saving Behavior of Habit Adjustment --Based on Behavioral Reasoning Theory
}

\author{
Changjin Liu', Yizhi Zhang', Yuhua Teng ${ }^{3}$, Yan Chen ${ }^{4, *}$ \\ ${ }^{I}$ School of Economics and Management, Jiangxi Hangkong University, 330045, Nanchang, China \\ ${ }^{2}$ South China Agriculture University, 510320, Guangzhou, China \\ ${ }^{3}$ Business College of Jiangxi Normal University, 330045, Nanchang, China \\ ${ }^{4}$ Guangdong University of Finance \& Economics, 510320, Guangzhou, China \\ *Corresponding Author.
}

\begin{abstract}
With the increasing public's energy consumption, the resident's energy-saving behavior has been paid more attention by all walks of life. Therefore, it is important to find out what factors influence the public's energy-saving behavior. The paper constructs a conceptual model of Chinese rural residents' energy-saving behavior of habit adjustment based on behavioral reasoning theory. It examines the energy-saving behavior of habit adjustment of rural residents on the basis of investigation data from rural residents in China. We reach the following conclusions: environment values not only significantly influence global motives (including attitudes about saving energy, subjective norms, perceived behavioral control) but also via the reasons for behavior have indirectly influences to it, thereby influencing rural residents' energy-saving intentions. The reasons for behavior have an indirect impact on rural residents' energy-saving intentions via the global motives. The reasons for behavior also directly influence the rural residents' energy-saving intentions. The attitudes about saving energy, the subjective norms and the perceived behavioral control have indirectly positive impacts on rural residents' energy-saving behavior of habit adjustment via the energy-saving intentions. The Poyang Lake Ecological Zone has an important ecological protection function in China. Promoting rural residents in there to save energy can effectively protect the environment.
\end{abstract}

Keywords: Chinese rural residents, energy-saving behavior of habit adjustment, reasons for energy-saving behavior, behavioral reasoning theory $(B R T)$

\section{Introduction}

From the statistics of China's National Energy Administration, in the first half of 2018, domestic residential electricity consumption maintained a double-digit growth. As a result, residents' energy consumption is second only to that of the industrial sector. Moreover, residents' increasing consumption of energy is also exerting tremendous pressure on energy supply and the environment. We have reached a consensus that our society should consider residents' energy-saving behaviors and lead them to reduce energy consumption, which will help to energy conservation. In recent years, with the continuous improvement of the living standards of rural residents in China, the per-capita living energy consumption of rural residents is increasing year by year. In 2013, the per-capita energy consumption of rural residents was 311 kilograms of standard coal. In 2014, it increased to 325 kilograms of standard coal, and reached 351 kilograms of standard coal in 2015(NBSC, 2016). Rural residents are the main rural consumers of energy as well as the main agricultural labor force. Implementing energy-saving behavior can not only reduce rural residents' energy consumption in daily life, but also cultivate their awareness of saving energy in production.

Researchers who have already examined residents' energy-saving behavior have identified three main factors influencing that behavior: psychological, situational and demographic. Psychological factors include environmental attitudes [1], perceived behavioral control, values, subjective norms [2]. Situational factors include low-carbon policies, economic policies, and command-controlled policies [3] and information about sustainable energy use [4]. Demographic characteristics include age, income, and education. As we can see, previous research on residents' energy-saving behavior focuses mainly on urban residents however there are significant differences between urban and rural residents in purchase choice behavior and daily use behavior. We believe that rural residents' energy-saving behavior should be distinguished from urban residents' energy-saving behavior and a study focusing on rural

ISSN: 0010-8189 
residents' energy-saving behavior is necessary.

Energy-saving behavior includes two ways of reducing and technological energy-saving actions. Samuelson (1990) [5] believed that energy-saving behavior is made up of energy-saving actions based on curtailment and actions based on the adoption of energy efficient technologies. Other researchers divide energy-saving behavior into three categories, such as Scott et al. (2000) [1]. Previous studies have found that different types of energy-saving behaviors result from different influencing factors however few scholars have studied different types of energy-saving behaviors and the differences between them. We consider that rural residents adjust their habits to save energy which is easy to do and have lower cost than the others behavior. So, we choose the energy-saving behavior of habit adjustment to study.

This paper defines rural residents' energy-saving behavior of habit adjustment as "saving energy through changing their daily habits, such as using energy-saving lamps."

To encourage rural residents to save energy by cultivating good daily habits, based on the behavioral reasoning theory (BRT), promoting rural residents in that area to saving energy can effectively protect the environment. We use the survey data and model to explore the rural residents' energy-saving behavior of habitual adjustment.

\section{Conceptual Framework and Hypotheses}

\subsection{Conceptual framework}

Westaby proposed behavioral reasoning theory in 2005, which is based on rational behavior theories such as planned behavior theory. Behavioral reasoning theory holds that traditional rational behavior theory neglects the insight into motivational mechanisms in behavior, while the concept of "behavioral reason" in behavioral reasoning theory makes up for this deficiency. Previous studies have proved the applicability of the behavioral reasoning theory in the field of environmental behavior researches [6,7]. Rural residents' energy-saving behavior of habit adjustment can be classified as an environmental behavior. To further study the process of rural residents' energy-saving behavior of habit adjustment, we construct a conceptual model based on behavioral reasoning to analyze the factors influencing rural residents' energy-saving behavior of habit adjustment and its mechanisms.

\subsection{Hypotheses}

\subsubsection{Environment values $\rightarrow$ behavioral reasons}

Studies on the factors influencing consumers' willingness to adopt new energy sources have found that values have a significant impact on reasons for adoption and reasons against adoption, both of which have a counteracting effect on the psychological formation of willingness to adopt new energy sources [7]. Rosanna et al. [8] has found that when consumers think products are matching their values, they adopt these products quickly. Wang et al [6] have found that environmentally consumption values significantly strengthened the reasons for or against behavior. Given the aforementioned discussion, we propose hypotheses H1a and $\mathrm{H} 1 \mathrm{~b}$ :

H1a: Rural residents' environmental values are positively associated with their reasons for adoption.

H1b: Rural residents' environmental values are negatively associated with their reasons against adoption.

\subsubsection{Environmental values $\rightarrow$ Global motives}

Environmental values are a value orientation held by individuals regarding the environment and related issues, which represent endorsements or supportive actions directed at environmental protection and environmental obligations. Most individuals with environmental values hold positive attitudes towards environmental behavior and are more easily influenced by others' positive environmental behavior patterns, which are close to their own value orientation. Faced with the obstacles to implementing new environmental behaviors, individuals with environmental values will be more confident in seeking to solve the problem because they are confident about the positive benefits of environmental behavior. Ibtissem [9] found that personal values positively affect environmental attitudes. Given this, we propose the hypothesis $\mathrm{H} 2 \mathrm{a}-\mathrm{H} 2 \mathrm{c}$ :

ISSN: 0010-8189 
H2a: Rural residents' environmental values are positively correlated with their attitudes about saving energy.

$\mathrm{H} 2 \mathrm{~b}$ : Rural residents' environmental values has a positive relationship with their subjective norm.

H2c: Rural residents' environmental values has a positive relationship with their perceived behavior control.

\subsubsection{Reasons $\rightarrow$ Global motives}

The reasons that individual use to support expected behaviors have a positive or negative impact on their global motives. Gupta et al. [11] found that consumers' reasons for adopting mobile payment are positively tied to their attitudes, while reasons against adoption have a negative impact on their attitudes. On the basis of the above research, we propose the hypothesis $\mathrm{H} 3 \mathrm{a}$ and $\mathrm{H} 3 \mathrm{~b}, \mathrm{H} 4 \mathrm{a}$ and $\mathrm{H} 4 \mathrm{~b}, \mathrm{H} 5 \mathrm{a}$ and $\mathrm{H} 5 \mathrm{~b}$ :

H3a: Rural residents' reasons for their behavior are positively associated with their attitudes about saving energy.

H3b: Rural residents' reasons against their behavior negatively affect their attitudess about saving energy.

H4a: Rural residents' reasons for their behavior are positively related to their subjective norms.

H4b: Rural residents' reasons against their behavior negatively associated with their subjective norms.

H5a: Rural residents' reasons for their behavior positively tied to their perceived behavioral control.

H5b: Rural residents' reasons against their behavior negatively related to their perceived behavioral control.

\subsubsection{Reasons $\rightarrow$ Energy-saving intention}

Individuals will have a positive attitude toward energy conservation and believe that they can overcome the obstacles they encounter in the process of conserving energy, but they may refuse to save energy for reasons such as an immature energy-saving technology. Wang et al [6] present reasons against behavior negatively affecting green consumption behavior intentions. We thus expect the following:

H6a: Rural residents' reasons for behavior are positively related with their energy-saving intentions.

H6b: Rural residents' reasons against behavior are negatively related with their energy-saving intentions.

\subsubsection{Global motives $\rightarrow$ Energy-saving intentions}

Attitudes represent a person's views on expected results of his or her own behavior, while subjective norm is the person's subjective perception of other people's accustomed behavior patterns. Yang et al [11] found that citizens' attitudes, subjective normalization and inherent perception act as potential mechanisms, which has a major impact on people's energy-saving behaviors. Wang et al [12] found that perceived behavioral control, behavioral attitude, and subjective norms positively affected farmers' standardized pesticide application behavior. Given this, we propose hypotheses $\mathrm{H} 7 \mathrm{a}-\mathrm{H} 7 \mathrm{c}$ :

H7a: Rural residents' attitudes about saving energy are positively related to their energy-saving intentions.

H7b: Subjective norms of rural residents are positively associated with their energy-saving intentions.

H7c: Rural residents' perceived behavioral control is positively tied to their energy-saving intentions.

2.2.6 Energy-saving intentions $\rightarrow$ Energy-saving behavior of habit adjustment

Behavioral reasoning theory thinks that a very important evaluation indicator of consumer behavior is intention. Many theoretical models propose that intentions serve as critical behavioral determinants, including the planned behavior theory and responsible environmental behavior theory. Numerous empirical analyses have proved the connection between urban residents' energy-saving intentions and energy-saving behavior, finding that residents' intentions has a positive impact on their energy-saving behavior [11]. We thus hypothesize the following:

H8: Rural residents' energy-saving intentions is positively tied to their energy-saving behavior of habit adjustment. 


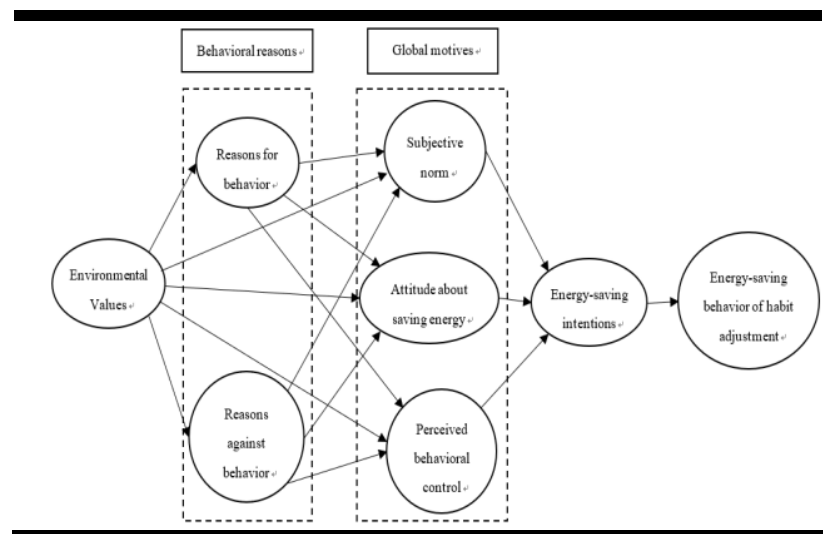

Fig 1: The conceptual model.

\section{Methods}

\subsection{Data collection}

To test the hypothesis, we designed a study among Chinese rural residents. The data was collected using in-person questionnaires in Jiangxi province in southeastern China. The survey was conducted in July 2018; 650 rural residents were randomly selected by Stratified random sampling method to participate in our survey. Partially completed survey forms were dropped, and 605 usable responses were considered for final analysis, a response rate of $93.08 \%$. Table 1 describes the individual characteristics of the final sample.

Table 1. Individual characteristic statistics.

\begin{tabular}{|c|c|}
\hline Demographics & Percentage \\
\hline \multicolumn{2}{|l|}{ Gender } \\
\hline 1. Male & 49.46 \\
\hline 2. Famale & 50.54 \\
\hline \multicolumn{2}{|l|}{ Age } \\
\hline 1. Under 30 years & 34.76 \\
\hline 2. $30-50$ years & 44.14 \\
\hline$\underline{3}$. Over 50 years & 21.10 \\
\hline \multicolumn{2}{|l|}{ Yearly income } \\
\hline 1. Less than $¥ 30000$ & 51.55 \\
\hline ㄹ. $¥ ¥ 30000-¥ 50000$ & 26.11 \\
\hline 3. More than $¥ 50000$ & 22.34 \\
\hline \multicolumn{2}{|l|}{ Education level } \\
\hline 1. Primary school or below primary & 33.19 \\
\hline 2. Middle school & 31.90 \\
\hline$\underline{3}$. High school or above high school & 34.91 \\
\hline \multicolumn{2}{|l|}{ Marriage status } \\
\hline 1. Married & 70.86 \\
\hline 2. Single & 29.14 \\
\hline
\end{tabular}

\subsection{Measurement}

Our investigation consisted of three steps. First, we designed a questionnaire that not only refers to the existing research scale, but also combined it with the actual situation of Jiangxi province in China. Second, we conducted a preliminary survey with the questionnaire, and basing on the results revised the questionnaire. After that, we used the final questionnaire to conduct a formal survey. 
The term "Energy-saving behavior of habit adjustment" (EB) is adapted from Mi et a [3]. It contains five items, such as "using the energy-saving lamps." According to factor analysis, two items were deleted.

The term "Energy-saving intentions" (EI)is developed by the research of Stern [13], 7 items like "I would like to change my daily energy use habits and save energy." are set. After the factor analysis, 4 items are retained.

The term "Environmental values" (EV) comes from the work of Stern et al. [13], and is reflected in three measurement items such as "Desire to protect the environment."

"Behavioral reasons" include the reasons for behavior (RFB) and reasons against behavior (RAB). This arose from Claudy et al [7] and Wang et al [12] Six items regarding the reasons for behavior were set, such as, "Using energy-saving products can reduce pollution;" two items were deleted according to the results of factor analysis; and four items about reasons against behavior included items such as, "The high price of energy-saving products."

The item "Attitudess about saving energy" (AT) includes six measurement items such as, "I think saving energy is a good habit."

The item "Subjective norms" (SN) included four items such as, "My family has been involved in energy conservation initiatives."

The item "Perceived behavioral control" (PBC) includes 5 items like "When it comes to difficulties in implementing energy-saving activities, I can always solve them."

\section{Result}

We conducted a confirmatory factor analysis to assess the properties of our measurement model. The results support unidimensional and convergent validity. The square root of average variances extracted (AVE) value of each variable is larger than the absolute value of the correlation coefficient, thus indicating the measures' discriminant validity. Table 2 shows that the AVE square root of each latent variable is significantly higher than the absolute value of its correlation coefficient with other variables, which means that the model variables have significant discriminatory validity.

\subsection{Model's estimated results}

The results of the reliability and validity analysis of the latent variables show that the variables can be used in structural equation model analysis. In this paper, survey data from 605 rural residents in Jiangxi Province were surveyed to test the hypothesis. The above hypotheses regarding the linkages among environmental values, behavioral reasons, attitude about saving energy, subjective norms, perceived behavioral control, energy-saving intentions and energy-saving behavior of habit adjustment were tested via structural equation modeling in AMOS. 22. Overall, the result shows that structural model fit was good with $\mathrm{CMIN} / \mathrm{DF}=1.904$, GFI=0.917, NFI $=0.918$, $\mathrm{IFI}=0.960, \mathrm{TLI}=0.955, \mathrm{CFI}=0.959, \mathrm{RMSEA}=0.039$.

Table 2 Discriminant validity

\begin{tabular}{ccccccccc}
\hline Constructs & XW & YY & AT & GF & KZ & VA & AG & RE \\
\hline XW & 0.779 & & & & & & & \\
YY & 0.452 & 0.799 & & & & & \\
AT & 0.311 & 0.640 & 0.832 & & & & \\
GF & 0.300 & 0.464 & 0.383 & 0.915 & & & \\
KZ & 0.296 & 0.549 & 0.460 & 0.539 & 0.751 & & \\
VA & 0.245 & 0.453 & 0.558 & 0.334 & 0.496 & 0.916 &
\end{tabular}




\begin{tabular}{ccccccccc} 
AG & 0.232 & 0.580 & 0.644 & 0.308 & 0.425 & 0.563 & 0.764 & \\
RE & -0.060 & -0.071 & -0.015 & -0.053 & 0.018 & 0.025 & 0.001 & 0.828 \\
\hline
\end{tabular}

Table 3 Results of structural model estimation

\begin{tabular}{cccccc}
\hline Path & Path coefficients & C.R & P & Hypotheses & Results \\
\hline $\mathrm{VA} \rightarrow \mathrm{RFB}$ & 0.461 & 9.726 & $* * *$ & $\mathrm{H} 1 \mathrm{a}$ & Supported \\
$\mathrm{VA} \rightarrow \mathrm{RAB}$ & 0.033 & 0.559 & 0.576 & $\mathrm{H} 1 \mathrm{~b}$ & Rejected \\
$\mathrm{VA} \rightarrow \mathrm{AT}$ & 0.179 & 5.164 & $* * *$ & $\mathrm{H} 2 \mathrm{a}$ & Supported \\
$\mathrm{VA} \rightarrow \mathrm{SN}$ & 0.261 & 3.7 & $* * *$ & $\mathrm{H} 2 \mathrm{~b}$ & Supported \\
$\mathrm{VA} \rightarrow \mathrm{PBC}$ & 0.458 & 5.912 & $* * *$ & $\mathrm{H} 2 \mathrm{c}$ & Supported \\
$\mathrm{RFB} \rightarrow \mathrm{AT}$ & 0.394 & 7.153 & $* * *$ & $\mathrm{H} 3 \mathrm{a}$ & Supported \\
$\mathrm{RAB} \rightarrow \mathrm{AT}$ & -0.004 & -0.263 & 0.792 & $\mathrm{H} 3 \mathrm{~b}$ & Rejected \\
$\mathrm{RFB} \rightarrow \mathrm{SN}$ & 0.346 & 3.514 & $* * *$ & $\mathrm{H} 4 \mathrm{a}$ & Supported \\
$\mathrm{RAB} \rightarrow \mathrm{SN}$ & -0.053 & -1.409 & 0.159 & $\mathrm{H} 4 \mathrm{~b}$ & Rejected \\
$\mathrm{RFB} \rightarrow \mathrm{PBC}$ & 0.394 & 3.691 & $* * *$ & $\mathrm{H} 5 \mathrm{a}$ & Supported \\
$\mathrm{RAB} \rightarrow \mathrm{PBC}$ & 0.018 & 0.44 & 0.66 & $\mathrm{H} 5 \mathrm{~b}$ & Rejected \\
$\mathrm{RFB} \rightarrow \mathrm{EI}$ & 0.227 & 3.151 & $* * *$ & $\mathrm{H} 6 \mathrm{a}$ & Supported \\
$\mathrm{RAB} \rightarrow \mathrm{EI}$ & -0.047 & -2.07 & $* *$ & $\mathrm{H} 6 \mathrm{~b}$ & Supported \\
$\mathrm{AT} \rightarrow \mathrm{EI}$ & 0.461 & 5.562 & $* * *$ & $\mathrm{H} 7 \mathrm{a}$ & Supported \\
$\mathrm{SN} \rightarrow \mathrm{EI}$ & 0.108 & 3.359 & $* * *$ & H7b & Supported \\
$\mathrm{PBC} \rightarrow$ EI & 0.148 & 3.969 & $* * *$ & H7c & Supported \\
$\mathrm{EI} \rightarrow \mathrm{EB}$ & 0.466 & 7.617 & $* * *$ & H8 & Supported \\
\hline
\end{tabular}

From table 3, we can find that environmental values were positively tied to the reasons for behavior (.461; $p<.01)$; providing support for $\mathrm{H1a}$, by indicating that rural residents with environmental values will put forward positive acceptance reasons when explaining their expected behavior. However, the environmental values have no significant influence on reasons against behavior, which invalidates $\mathrm{H} 1 \mathrm{~b}$, because rural residents with environmental values pay more attention to the environmental benefits of their behavior, and less about its drawbacks (such as relatively high prices, insufficiently mature technology, etc.). The relationship of environmental values and attitudes about saving energy $(.179, \mathrm{p}<.01, \mathrm{H} 2 \mathrm{a})$, subjective norms $(.261, \mathrm{p}<.01, \mathrm{H} 2 \mathrm{~b})$, and perceived behavioral control $(.458, \mathrm{p}<.01, \mathrm{H} 2 \mathrm{c})$ is be proved effective, showing that rural residents with stronger environmental values and their attitudes about saving energy will be more positive, more susceptible to subjective norms, and have stronger ability to remove behavioral barriers through self-perception. The reason for behavior positively affects subjective norms (.346, $\mathrm{p}<.01)$, attitudes about saving energy $(.304, \mathrm{p}<.01)$, and perceived behavioral control $(.394, \mathrm{p}<.01)$. This is also positively associated with energy-saving intentions (.227, p<.01), consistent with H3a, H4a, H5a and H6a, which indicates that the more reasons individuals find for acceptance, the more vulnerable they are to the influence of subjective norms. At the same time, the acceptance of reasons will give rural residents a positive attitude toward the energy-saving behavior of habit adjustment, and strengthen their ability to perceive and solve the obstacles encountered in energy-saving. The reasons for behavior will increase the rural residents' intentions to engage in energy-saving behavior. Reasons against behavior are positively related to energy-saving intentions $(-.047, \mathrm{p}<.05)$; providing support for H6b, and showing that the reasons against behavior directly affect rural residents' willingness to save energy. The more reasons residents have against performing energy-saving behavior, the lower their willingness to save energy. However, reasons against behavior had no significant effect on subjective norms, attitude about saving energy, or perceived behavioral control, thus invalidating $\mathrm{H} 3 \mathrm{~b}, \mathrm{H} 4 \mathrm{~b}$ and $\mathrm{H} 5 \mathrm{~b}$.

Subjective norms, attitudes about saving energy, and perceived behavioral control have significantly positive effects on energy-saving intentions, providing support for $\mathrm{H7a}, \mathrm{H} 7 \mathrm{~b}$, and H7c. The path coefficients are 0.108 ( $\mathrm{p}<.01$ ), $0.461(\mathrm{p}<.01)$, and $0.148(\mathrm{p}<.01)$, indicating that rural residents with positive energy-saving attitudes, actively perceive other people's behavior patterns, and stronger perception of behavior control will strengthen their energy-saving intentions. 
Energy-saving intentions are positively tied to their energy-saving behavior of habit adjustment $(.466, \mathrm{p}<.01, \mathrm{H} 8)$. This shows that the stronger rural residents' energy-saving intentions, the more energy-saving behavior of habit adjustment they will implement.

\section{Conclusion}

Based on behavioral reasoning theory, this paper constructs a conceptual model of factors influencing Chinese rural residents' energy-saving behavior of habit adjustment. It examines the factors influencing on the energy-saving behavior of habit adjustment of Chinese rural residents through structural equation modeling of the data from Chinese rural residents in Jiangxi Province. Based on our survey, this study draws the following conclusions. (1) Rural residents' environmental values not only directly affect attitudes about saving energy, subjective norms, and perceived behavioral control, but they also indirectly influence attitudes about saving energy, subjective norms, and perceived behavioral control through affecting reasons for behavior, thereby affecting willingness to save energy. (2) Reasons for behavior affect rural residents' energy-saving intentions through attitudes about saving energy, subjective norms, and perceived behavioral control. At the same time, the reasons for behavior and the reasons against behavior are directly related to energy-saving intentions. However, the reasons for behavior and the reasons against behavior have different effects on the energy-saving intentions. Specifically, the reasons for behavior have a positive impact on the energy-saving intentions, while the reasons against behavior weaken the energy-saving intentions. (3) Attitudes about saving energy, subjective norms, and perceived behavioral control influence energy-saving behavior of habit adjustment through energy-saving intentions. (4) Energy-saving intentions directly and positively associate with energy-saving behavior of habit adjustment.

\section{Acknowledgments}

This work was supported by the National the Natural Science Foundation of China (NO.71864018, NO.71663032), Guangdong Natural Science Foundation of China (Grant No.2018A030313496), Guangdong Social Science Planning Fund Program of China (Grant No. GD14YYJ01).

Yan Chen and Yuhua Teng contributed to research design and data collection; Yizhi Zhang completed the empirical analysis; Yan Chen performed the translation between English and Chinese for the questionnaire; Changjin Liu and Yizhi Zhang carried out the research about discussions and completed the writing of this article.

\section{References}

[1] Scott, D.; Parker, P.; Rowlands, I. Determinants of energy efficiency behaviors in the home. Environments. 28, 73-76, 2000.

[2] Y.X. Zhang, Z.H. Wang. Determinants of energy saving intention in organizations-A study of knowledge workers based on the theory of planned behavior. Journal of Beijing Institute of Technology (Social Sciences Edition). 6, 7-13, 2012.

[3] L.Y. Mi. Research on urban residents low carbonization energy consumption behavior and police guidance. Doctoral dissertation, China University of Mining and Technology, Xuzhou City, Jiangsu Province, China.2011.

[4] Gyberg, P.; Palm, J. Influencing households' energy behavior-How is this done and on what premises? Energy Policy. 7, 2807-2813, 2009.

[5] Samuelson, C.D. Energy conservation: A social dilemma approach. Social Behavior. 5, 207-230, 1990.

[6] J.G. Wang, W.Q. Du. Empirical research on green consumption using behavior reasoning theory, Journal of Dalian university of technology (Social Sciences). 2, 13-18, 2016.

[7] Claudy, M.C; Peterson, M.; Driscoll A. Understanding the attitude-behavior gap for renewable energy systems using behavioral reasoning theory. Journal of Micromarketing, 33, 273-287, 2013.

[8] Rosanna, G.; Bardhi, F.; Friedrich, C. Overcoming consumer resistance to innovation overcoming consumer resistance to innovation. MIT Sloan Management Review. 48, 82-88, 2007.

[9] Ibtissem, M.H. Application of value beliefs norms theory to the energy conservation behavior. Journal of 
Sustainable Development. 3, 2010.

[10] Gupta, A.; Arora, N. Understanding determinants and barriers of mobile shopping adoption using behavioral reasoning theory. Journal of Retailing and Consumer Services. 36, 1-7, 2017.

[11] J.R. Yang, Y. Wang. Research on energy-saving behaviors of urban residents based on TPB. Collected Essays on Finance and Economics. 5, 105-112, 2018.

[12] J.H. Wang, Y.T. Ma, L.H. Wu. Study on conduction path and influencing factors of farmers' regulating pesticide application behavior. Journal of Northwest A\&F University (Social Sciences Edition). 4, 146-154, 2016.

[13] Stern, P.C, Dietz, T. Abel. A value-belief -norm theory of support for social movements: The case of environmentalism. Human Ecology Review. 6, 81-97, 1999. 